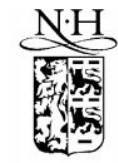

ELSEVIER
International Journal of Industrial Organization 17 (1999) 903-914
International Joumal of Industrial Organization

\title{
Quality choice and vertical integration
}

\author{
Nicholas Economides* \\ Stern School of Business, New York University, New York, NY 10012-1126, USA
}

Accepted 29 October 1997

\begin{abstract}
We show that, despite coordination in the quality level of the components that they provide, independent vertically-related (disintegrated) monopolists will provide products of lower quality level than a sole integrated monopolist. Further, the integrated monopolist achieves higher market coverage, higher consumer surplus, and higher profits. We establish these results for any distribution of preferences in the standard model of quality differentiation. Despite the lower quality, we also show that, for a wide class of cost functions, price will be higher in a market of independent vertically-related monopolists. All results are the effects of the interaction of double-marginalization, occurring in the market of independent monopolists, with the choice of quality. (c) 1999 Elsevier Science B.V. All rights reserved.
\end{abstract}

Keywords: Quality; Duopoly; Vertical integration

JEL classification: L1; D4

\section{Introduction}

Many goods are composed of complementary components. In some of these, the quality of the composite good is the minimum of the qualities of the component parts. For example, a long distance phone call requires the use of long distance lines as well as local lines at the two terminating points. The fidelity of sound in such a phone call is the minimum of the qualities of the three services used. In

\footnotetext{
* Tel.: + 1-212-998-0864; fax: + 1-212-995-4218.

E-mail address: neconomi@stern.nyu.edu; www: http://raven.stern.nyu.edu/networks/ (M. Economides)
} 
such situations, if different links are owned by different firms (as in the postAT\&T-divestiture world), firms need to coordinate in the determination of the quality level of the composite good.

In this paper we examine the simple case in which there is only one composite good demanded. We compare the world where both links are owned by the same firm with the world where they are owned by separate entities (dual verticallyrelated disintegrated monopolists). As far as pricing is concerned, this comparison has been done in the third chapter of Cournot (1927). ${ }^{1}$ He found that dual monopolists are not able to appropriate the full benefits of a price reduction they initiate and therefore face in effect a more inelastic demand and quote higher prices than the sole vertically integrated monopolist. This phenomenon has been known as "double marginalization." 2 The focus of this paper is the effect of double marginalization on the quality of the components and of the composite good.

When only the composite good is demanded and its quality is the minimum of the qualities of the components, there is no incentive for either of the dual monopolists to produce components of different qualities even in a non-cooperative setting; the integrated monopolist does the same. Thus, in both ownership structures, firms are coordinating the quality levels of the components. The interesting question is the differences in the coordinated level of quality across regimes. Put differently, what kind of distortion in the provision of quality does double marginalization create?

We show that, for any distribution of preferences, the dual monopolists produce components of lower quality than the integrated sole monopolist. Therefore, vertical disintegration has a significant adverse effect on quality provision, besides the known effect of price increase. This result can be explained in intuitive terms as follows: because of double marginalization, the impact of marginal improvements in quality on price is higher under dual ownership. Thus, independent monopolists can achieve the same strategic effects while providing lower quality and saving on costs.

We also show that market coverage, consumers surplus, and profits are all lower under vertical disintegration. We further show that, for a wide class of cost functions and any distribution of preferences, prices will be higher under dual ownership, despite the lower quality. Thus, vertical disintegration hurts consumers through both higher prices and lower quality. ${ }^{3}$

\footnotetext{
${ }^{1}$ See also Sonnenschein (1968).

${ }^{2}$ Cournot uses a simultaneous price-setting game for complements that is very similar to the well-known simultaneous quantity-setting game for substitutes. Some later authors have used games of sequential choice with very similar results.

${ }^{3}$ Note that this paper analyzes bilateral monopoly quality provision and compares it with the provision of quality by a single integrated firm. Thus, this paper does not discuss incentives for non-price discrimination that can arise, for example, in the present state of the telecommunications market in the United States when a bottleneck monopolist also provides the monopolized input to a competitive sector, as in Economides (1997).
} 
The rest of the paper is organized as follows. Section 2 outlines the preference and cost structures. Section 3 discusses the equilibrium of a vertically integrated monopolist. Section 4 discusses the subgame-perfect equilibrium of two verticallyrelated disintegrated monopolists. In Section 5, we make comparisons on quality levels across ownership structures. In Section 6, we compare price levels at the full-fledged equilibria. Extensions are presented in Section 7. Section 8 contains concluding remarks.

\section{Preferences and costs}

Consider a market for good AB that is composed of components $\mathrm{A}$ and $\mathrm{B}$ combined in a $1: 1$ proportion. Suppose that the quality of the composite good is the minimum of the quality levels of its components, $q \equiv q_{\mathrm{AB}}=\min \left(q_{\mathrm{A}}, q_{\mathrm{B}}\right){ }^{4}$. Let each consumer have a different marginal willingness to pay for quality, so that the utility of a consumer of type $\theta$ is ${ }^{5}$

$$
U_{\theta}(q, p)=\theta q-p,
$$

where $p$ is the price. Let $\theta$ be distributed on $[0,1]$ with cumulative distribution function $F(\theta)$.

We assume zero marginal costs. ${ }^{6}$ Fixed costs of providing each component are separable, $\phi_{\mathrm{A}}\left(q_{\mathrm{A}}\right)+\phi_{\mathrm{B}}\left(q_{\mathrm{B}}\right)$. Thus, there are no cost savings from joint provision of $\mathrm{A}$ and $\mathrm{B}$. We assume that both cost functions are increasing and convex in quality, $\phi_{\mathrm{A}}^{\prime}(q), \phi_{\mathrm{B}}^{\prime}(q)>0 ; \phi_{\mathrm{A}}^{\prime \prime}(q), \phi_{\mathrm{B}}^{\prime \prime}(q)>0$.

\section{Vertically integrated monopolist (sole ownership)}

We first consider a vertically integrated monopolist who produces a single version of each component, $\mathrm{A}$ and $\mathrm{B}$, and sells them as a single product $\mathrm{AB}$. The willingness-to-pay of consumers depends on the quality of the composite good, which is the minimum of $q_{\mathrm{A}}$ and $q_{\mathrm{B}}$. Since there is never a revenue gain associated with increasing a component's quality above the highest quality component with which it might be paired, and since component costs increase with quality, the monopolist will choose the same quality for both components, so that $q=q_{\mathrm{A}}=q_{\mathrm{B}}$.

We assume that price discrimination is impossible; thus, the monopolist will quote a single $p$ for the good $\mathrm{AB}$. The marginal consumer $\theta^{*}$, who is indifferent

\footnotetext{
${ }^{4}$ This formulation allows a firm only to reduce the value of the composite good. This is in contrast with the model of Economides and Salop (1992) where each component adds to the value of the other.

${ }^{5}$ Clearly this can be thought of as a normalization of the units of $q$ with the appropriate adjustment of the distribution of $\theta$.

${ }^{6}$ The results can easily be reinterpreted if there are constant marginal costs.
} 
between buying or not buying $\mathrm{AB}$, is defined by

$$
\theta^{*} q-p=0 \Leftrightarrow \theta^{*}(p, q)=p / q
$$

All consumers of types $\theta \in\left[\theta^{*}, 1\right]$ will purchase the good; thus the monopolist's demand is

$$
D=1-F\left(\theta^{*}\right) \text {. }
$$

The monopolist's profits are: ${ }^{7}$

$$
\Pi_{\mathrm{S}}(p, q)=p D-\phi_{\mathrm{A}}(q)-\phi_{\mathrm{B}}(q) .
$$

Although the choices of the integrated monopolist can be thought as taking place simultaneously, it is useful for the comparisons that we will be making below to consider them as sequential, with the quality choice preceding the price choice. Of course, breaking the optimization in two stages does not alter its solution. In the second stage, the integrated monopolist chooses price so that ${ }^{8}$

$$
\partial \Pi_{\mathrm{S}} / \partial p=1-F(p / q)-(p / q) f(p / q)=1-F\left(\theta_{\mathrm{S}}^{*}\right)-\theta_{\mathrm{S}}^{*} f\left(\theta_{\mathrm{S}}^{*}\right)=0 .
$$

Let the marginal consumer defined by (5) be $\theta_{\mathrm{S}}^{*}$, and the implied equilibrium price in this stage be $p_{\mathrm{S}}(q)$. Then the equilibrium profits of the last stage,

$$
\Pi_{\mathrm{S}}\left(p_{\mathrm{S}}(q), q\right),
$$

are the objective function in the first stage; the monopolist chooses quality $q$ to maximize them. Let his quality choice be $q_{\mathrm{S}}$. The corresponding equilibrium price is $p_{\mathrm{S}}\left(q_{\mathrm{S}}\right)$. The resulting equilibrium profits of the integrated monopolist are

$$
\Pi_{\mathrm{S}}^{*} \equiv \Pi_{\mathrm{S}}\left(p_{\mathrm{S}}\left(q_{\mathrm{S}}\right), q_{\mathrm{S}}\right) \text {. }
$$

\section{Independent unintegrated monopolists (dual ownership)}

We now consider the case when each component is produced by a different (independent) monopolist. The upstream monopolist produces A and the downstream monopolist produces $\mathrm{B}$. They are sold at prices $p_{\mathrm{A}}$ and $p_{\mathrm{B}}$, respectively, so that the composite good $\mathrm{AB}$ is available at price $p=p_{\mathrm{A}}+p_{\mathrm{B}}$. The composite good has quality $q=\min \left(q_{\mathrm{A}}, q_{\mathrm{B}}\right)$. All consumers with marginal willingness to pay for quality larger than $\theta^{*}=p / q$ purchase the good, so that demand is $D=1-F\left(\theta^{*}\right)$, as before. Profits for the two firms are:

\footnotetext{
${ }^{7}$ We use the subscript "S" for "sole ownership" by a monopolist of both components.

${ }^{8}$ The second order condition, $\partial^{2} \Pi_{\mathrm{S}} / \partial p^{2}=-2 f(p / q) / q-\left(p / q^{2}\right) f^{\prime}(p / q)<0 \Leftrightarrow \theta f^{\prime}(\theta) / f(\theta)>-2$, puts a mild restriction on the acceptable distributions.
} 


$$
\begin{aligned}
\Pi_{\mathrm{A}}\left(p_{\mathrm{A}}, p_{\mathrm{B}}, q_{\mathrm{A}}, q_{\mathrm{B}}\right) & =p_{\mathrm{A}} D-\phi_{\mathrm{A}}\left(q_{\mathrm{A}}\right) \text { and } \Pi_{\mathrm{B}}\left(p_{\mathrm{A}}, p_{\mathrm{B}}, q_{\mathrm{A}}, q_{\mathrm{B}}\right) \\
& =p_{\mathrm{B}} D-\phi_{\mathrm{B}}\left(q_{\mathrm{B}}\right) .
\end{aligned}
$$

In the second stage, firms choose prices simultaneously. ${ }^{9}$ Firm A's profit maximization condition is

$$
\partial \Pi_{\mathrm{A}} / \partial p_{\mathrm{A}}=1-F(p / q)-\left(p_{\mathrm{A}} / q\right) f(p / q)=0 .
$$

Firm $\mathrm{B}$ has an identical profit maximization condition with $p_{\mathrm{A}}$ substituted with $p_{\mathrm{B}}$. Thus, $p_{\mathrm{A}}=p_{\mathrm{B}}=p / 2$, and the profit maximization conditions can be written as ${ }^{10}$

$$
\partial \Pi_{\mathrm{A}} / \partial p_{\mathrm{A}}=\partial \Pi_{\mathrm{B}} / \partial p_{\mathrm{B}}=1-F\left(\theta_{\mathrm{D}}^{*}\right)-\theta_{\mathrm{D}}^{*} f\left(\theta_{\mathrm{D}}^{*}\right) / 2=0 .
$$

Let the marginal consumer defined by $(8)$ be $\theta_{\mathrm{D}}^{*}$, and the implied equilibrium price in this stage be $p_{\mathrm{D}}(q)$, where "D" stands for "dual ownership". Comparison of (8) with (5) reveals that the intensity of preference for quality that characterizes the marginal consumer is higher in dual ownership than in sole ownership, ${ }^{11}$

$$
\theta_{\mathrm{S}}^{*}<\theta_{\mathrm{D}}^{*}
$$

This implies that market coverage is lower with dual ownership than with sole ownership.

Note that the maximization problems of the integrated and the dual monopolists are defined for arbitrary quality levels, which do not have to be the same (but can be the same). Moreover, quality does not appear by itself in (5) and (8), since these are defined only in terms of market coverage. Thus, the comparison of market coverages across market structures, in (9), is not contingent on the quality being the same in the two cases.

Lemma 1. The intensity of preference for quality that characterizes the marginal consumer in dual ownership is higher than in integrated (sole) monopoly, $\theta_{S}^{*}<\theta_{D}^{*}$. Thus, it follows that market coverage is lower in dual ownership.

If we start with the same quality level in the two market structures, prices will be higher in independent ownership,

$$
p_{\mathrm{S}}(q)<p_{\mathrm{D}}(q) \text {. }
$$

This double marginalization effect was first observed by Cournot (1927).

\footnotetext{
${ }^{9}$ This is in the Cournot tradition. Results are similar if prices are chosen sequentially.

${ }^{10}$ The second order condition is equivalent to $\theta f^{\prime}(\theta) / f(\theta)>-4$; it is clearly implied by the second order condition of joint ownership.

${ }^{11}$ To prove this, evaluate $\partial \Pi_{\mathrm{S}} / \partial p$ at the profit maximization condition of independent ownership: $\partial \Pi_{\mathrm{S}}\left(p_{\mathrm{D}}(q), q\right) / \partial p=-\theta_{\mathrm{D}}^{*} f\left(\theta_{\mathrm{D}}^{*}\right) / 2<0$. By the concavity of $\Pi_{\mathrm{S}}$ in $p$, it follows that $\theta_{\mathrm{S}}^{*}<\theta_{\mathrm{D}}^{*}$.
} 
Essentially, the root cause of the price difference is the inability of each of the dual monopolists to appropriate the full benefits of a decrease in its own price, which clearly the integrated monopolist is able to do.

Theorem 1 (Cournot). If the quality level is the same under both ownership structures, the integrated (sole) monopolist will choose a lower price than the dual vertically-related monopolists.

Anticipating the equilibrium of the second stage, each firm chooses in the first stage the quality of its component. There is no point for either of the monopolists to choose a higher quality than that of the complementary good. Therefore, the dual monopolists set identical qualities, $q=q_{\mathrm{A}}=q_{\mathrm{B}}$. The particular level of $q$ that they choose maximizes each firm's profits,

$$
\Pi_{\mathrm{A}}\left(p_{\mathrm{D}}(q) / 2, p_{\mathrm{D}}(q) / 2, q, q\right)=\Pi_{\mathrm{B}}\left(p_{\mathrm{D}}(q) / 2, p_{\mathrm{D}}(q) / 2, q, q\right) .
$$

Let $q_{\mathrm{D}}$ be the quality choice of both firms; the implied market price for composite good $\mathrm{AB}$ is $p_{\mathrm{D}}\left(q_{\mathrm{D}}\right)$. Finally, the equilibrium profits per firm are

$$
\Pi_{\mathrm{A}}^{*} \equiv \Pi_{\mathrm{B}}^{*} \equiv \Pi_{\mathrm{A}}\left(p_{\mathrm{D}}\left(q_{\mathrm{D}}\right) / 2, p_{\mathrm{D}}\left(q_{\mathrm{D}}\right) / 2, q_{\mathrm{D}}\right) .
$$

\section{Quality and welfare comparisons}

We have already seen in Theorem 1 that, starting with the same quality level at the first stage of the game, the market of dual monopolists will have a higher price than that of the integrated sole monopolist. We now examine the incentives of firms to provide different quality levels in different ownership structures. For this, it is sufficient to examine the total impact of marginal quality changes, directly as well as indirectly through prices, to equilibrium profits in each ownership structure. $^{12}$

To evaluate the marginal effects of quality on profits $\mathrm{d} \Pi_{\mathrm{S}}^{*} / \mathrm{d} q$ and $\mathrm{d}\left(\Pi_{\mathrm{A}}^{*}+\right.$ $\left.\Pi_{\mathrm{B}}^{*}\right) / \mathrm{d} q$ we need to differentiate totally (6) and (12) and substitute the corresponding $\mathrm{d} p / \mathrm{d} q$ from total differentiation of the price first order conditions (5) and (8), respectively. We first find $\mathrm{d} p / \mathrm{d} q$. In both (5) and (8), price $p$ influences the profit maximization condition only through $\theta^{*}$. Thus, for both (5) and (8) we find that $^{13}$

\footnotetext{
${ }^{12}$ Since both ownership structures have the same cost structure, the direct impact of quality change on costs is the same in both ownership structures. Any difference will have to arise from the different effects of quality changes on price in the two ownership structures.

${ }^{13}$ For example, naming $R(p, q)$ the expression of the first order condition $(5), R(p, q)=1-F\left(\theta^{*}\right)-$ $\theta^{*} f\left(\theta^{*}\right)$, and applying the implicit function theorem, we have $\mathrm{d} p / \mathrm{d} q=-\left[\left(\partial R / \partial \theta^{*}\right)\left(\partial \theta^{*} / \partial q\right)\right] /[(\partial R /$ $\left.\left.\partial \theta^{*}\right)\left(\partial \theta^{*} / \partial p\right)\right]=-\left(\partial \theta^{*} / \partial q\right) /\left(\partial \theta^{*} / \partial p\right)=-\left(-p / q^{2}\right) /(1 / q)=p / q=\theta^{*}$, and similarly for Eq. (8).
} 


$$
\mathrm{d} p / \mathrm{d} q=-\left(\partial \theta^{*} / \partial q\right) /\left(\partial \theta^{*} / \partial p\right)=\theta^{*}
$$

Although the formula for $\theta^{*}$ is the same, the impact of quality improvements, starting from the same quality level, is different in the two regimes. This is because $\theta^{*}$ is different in each case because equilibrium prices differ. Under dual ownership, price is higher, market coverage is lower, and $\theta^{*}$ is higher. Thus, for dual ownership, quality improvements have a bigger impact on price. We focus next on the impact of quality changes on profits.

To see the impact of quality improvements on profits in each ownership structure, we evaluate $\mathrm{d} \Pi_{\mathrm{S}}^{*} / \mathrm{d} q$ and $\mathrm{d}\left(\Pi_{\mathrm{A}}^{*}+\Pi_{\mathrm{B}}^{*}\right) / \mathrm{d} q:{ }^{14}$

$$
\begin{aligned}
& \mathrm{d} \Pi_{\mathrm{S}}^{*} / \mathrm{d} q=(\mathrm{d} p / \mathrm{d} q) D-\phi_{\mathrm{A}}^{\prime}(q)-\phi_{\mathrm{B}}^{\prime}(q)=\theta^{*} D-\phi_{\mathrm{A}}^{\prime}(q)-\phi_{\mathrm{B}}^{\prime}(q) \\
& =\left[\Pi_{\mathrm{S}}^{*}+\phi_{\mathrm{A}}(q)+\phi_{\mathrm{B}}(q)\right] / q-\phi_{\mathrm{A}}^{\prime}(q)-\phi_{\mathrm{B}}^{\prime}(q), \\
& \begin{aligned}
\mathrm{d}\left(\Pi_{\mathrm{A}}^{*}+\Pi_{\mathrm{B}}^{*}\right) / \mathrm{d} q & =2 \mathrm{~d} \Pi_{\mathrm{A}}^{*} / \mathrm{d} q=(\mathrm{d} p / \mathrm{d} q) D-\phi_{\mathrm{A}}^{\prime}(q)-\phi_{\mathrm{B}}^{\prime}(q) \\
& =\theta^{*} D-\phi_{\mathrm{A}}^{\prime}(q)-\phi_{\mathrm{B}}^{\prime}(q) \\
& =\left[\Pi_{\mathrm{A}}^{*}+\Pi_{\mathrm{B}}^{*}+\phi_{\mathrm{A}}(q)+\phi_{\mathrm{B}}(q)\right] / q-\phi_{\mathrm{A}}^{\prime}(q)-\phi_{\mathrm{B}}^{\prime}(q) .
\end{aligned}
\end{aligned}
$$

The integrated monopolist realizes the highest possible profits in the absence of price discrimination,

$$
\Pi_{\mathrm{S}}^{*}>\Pi_{\mathrm{A}}^{*}+\Pi_{\mathrm{B}}^{*} .
$$

In combination with (14) and (15), this implies that, for any $q$,

$$
\mathrm{d} \Pi_{\mathrm{S}}^{*} / \mathrm{d} q>\mathrm{d}\left(\Pi_{\mathrm{A}}^{*}+\Pi_{\mathrm{B}}^{*}\right) / \mathrm{d} q .
$$

Thus, marginal improvements in quality have a bigger positive impact on revenues and profits under sole monopoly than under dual monopoly. This is because the sole monopolist is able to appropriate all the revenue benefit of an increase in quality, while dual monopolists only keep part of the revenue increase. Since quality improvements have a bigger impact on profits for the sole monopolist, he chooses a higher quality level. Formally, on the assumption that the equilibrium profits are concave in quality choice, it follows from (17) that the equilibrium quality is higher for the integrated monopolist, $q_{\mathrm{S}}>q_{\mathrm{D}}$.

Theorem 2. At the subgame-perfect equilibrium of the quality-price game, the dual (disintegrated) monopolists choose a lower quality level than the integrated sole monopolist.

\footnotetext{
${ }^{14}$ A second term of $\mathrm{d} \Pi_{\mathrm{S}}^{*} / \mathrm{d} q$, that is $p \mathrm{~d} D / \mathrm{d} q=-p f(p / q)\left[-p / q^{2}+p / q^{2}\right]$, vanishes since the term in brackets is zero. The same is true for the second term of $\left(\mathrm{d} \Pi_{\mathrm{A}}^{*}+\mathrm{d} \Pi_{\mathrm{B}}^{*}\right) / \mathrm{d} q$.
} 
This result can also be explained through an analysis of the strategic impact of quality improvements. We have shown that, compared to the case of integrated monopoly, because of double marginalization, in dual ownership, marginal increases in quality have a bigger impact on price. ${ }^{15}$ Being able to sell the same quality at a higher price than under integrated monopoly, the dual monopolists choose a lower quality level, which is less costly to produce. Of course, the dual monopolists do not realize higher profits than in sole ownership, since their prices are too high because of double marginalization.

The lower market coverage with dual ownership established in Lemma 1 directly implies that, from the point of view of the consumers, dual ownership is Pareto inferior to sole ownership. A consumer with $\theta<\theta_{\mathrm{S}}$ is indifferent across ownership structures because he does not buy the good in either of them. A consumer with $\theta \in\left(\theta_{\mathrm{S}}, \theta_{\mathrm{D}}\right)$ strictly prefers sole ownership because in that regime he realizes a positive surplus, while with dual ownership he does not buy and therefore has zero surplus. Finally, a consumer with $\theta>\theta_{\mathrm{D}}$ is better off in sole ownership if and only if

$$
\theta q_{\mathrm{S}}-p_{\mathrm{S}}>\theta q_{\mathrm{D}}-p_{\mathrm{D}} \Leftrightarrow \theta>\left(p_{\mathrm{S}}-p_{\mathrm{D}}\right) /\left(q_{\mathrm{S}}-q_{\mathrm{D}}\right) .
$$

Now, from Lemma $1, p_{\mathrm{D}} / q_{\mathrm{D}}>p_{\mathrm{S}} / q_{\mathrm{S}}$. This implies

$$
p_{\mathrm{D}} / q_{\mathrm{D}}>\left(p_{\mathrm{S}}-p_{\mathrm{D}}\right) /\left(q_{\mathrm{S}}-q_{\mathrm{D}}\right) \text {. }
$$

Thus, $\theta>p_{\mathrm{D}} / q_{\mathrm{D}} \Rightarrow \theta>\left(p_{\mathrm{S}}-p_{\mathrm{D}}\right) /\left(q_{\mathrm{S}}-q_{\mathrm{D}}\right)$; that is, consumers who buy under the regime of dual ownership would be better off under sole ownership. Thus, all types of consumers are weakly better off under sole ownership. Only the consumers who buy nothing under both regimes are indifferent across market structures, and all other consumers are strictly better off under sole ownership. Since profits are globally the highest at sole ownership, firms are also better off under sole ownership.

Theorem 3. The sole ownership equilibrium is Pareto superior to the subgameperfect dual ownership equilibrium for both consumers and firms.

Because prices for the same quality are higher under dual ownership while quality is lower in that regime, there can be no general deduction about the comparison of equilibrium prices. However, the next section shows that, for a wide class of cost functions and any distribution of preferences, the equilibrium price is higher in bilateral monopoly than in integrated monopoly.

\footnotetext{
${ }^{15}$ Note that there is no contradiction between the impact of quality improvements on price and on revenue: in dual ownership the impact of a quality change on price is higher and the impact of a quality change on profits is lower compared to the respective cases in sole ownership.
} 


\section{Price comparisons for power cost functions}

Suppose that the fixed costs of quality are a power function of $q, \phi_{\mathrm{A}}(q)=$ $\phi_{\mathrm{B}}(q)=c q^{a} / 2$, so that the cost of producing both components is $\phi_{\mathrm{A}}(q)+\phi_{\mathrm{B}}(q)=$ $c q^{a}, a>1$. We will show that for exponents $a \geqslant 2$, the price for the composite good under dual ownership is higher than under sole monopoly, despite the provision of a lower quality level under dual ownership.

We have established the marginal relationship between quality and price at the price equilibrium in both ownership structures as

$$
\mathrm{d} p / \mathrm{d} q=p / q .
$$

Solving this as a differential equation we have

$$
p=k q,
$$

where the $k=\theta^{*}$ is defined by (5) in sole ownership as $k_{\mathrm{S}}$, and by (8) in dual ownership as $k_{\mathrm{D}}$ :

$$
\begin{aligned}
& 1-F\left(k_{\mathrm{S}}\right)-k_{\mathrm{S}} f\left(k_{\mathrm{S}}\right)=0, \\
& 1-F\left(k_{\mathrm{D}}\right)-k_{\mathrm{D}} f\left(k_{\mathrm{D}}\right) / 2=0 .
\end{aligned}
$$

As we have shown earlier, $k_{\mathrm{S}}<k_{\mathrm{D}}$.

The quality choice in each regime is defined by the solution of (14) and (15), respectively. By inspection of (14) and (15) we note that, at each of these choices, for the class of cost functions considered in this section, market-wide equilibrium revenues in each regime are proportional to quality,

$$
p D=q \theta^{*} D=a c q^{a} \Rightarrow p=a c q^{a} /(1-F(k)) .
$$

Eliminating the price between (21) and (22), we define the equilibrium quality as a function of $k\left(k_{\mathrm{S}}\right.$ or $\left.k_{\mathrm{D}}\right)$ :

$$
q=v[k(1-F(k))]^{1 /(a-1)},
$$

where $v \equiv(a c)^{-1 /(a-1)}$. Then the equilibrium price is

$$
p=v\left[k^{a}(1-F(k))\right]^{1 /(a-1)} .
$$

Differentiating $p$ with respect to $k$ we have

$$
\mathrm{d} p / \mathrm{d} k=v k^{a-1}[a(1-F(k))-k f(k)]\left[k^{a}(1-F(k))\right]^{(2-a) /(a-1)} /(a-1) .
$$

In view of $\left(5^{\prime}\right)$ and $\left(8^{\prime}\right), \mathrm{d} p / \mathrm{d} k>0$ for $a \geqslant 2$ for $k \in\left[k_{\mathrm{S}}, k_{\mathrm{D}}\right)$, and exceptionally $\mathrm{d} p / \mathrm{d} k=0$ at $k=k_{\mathrm{D}}$ when $a=2$. Since $k_{\mathrm{S}}<k_{\mathrm{D}}$, it follows from (25) that $p_{\mathrm{S}}<p_{\mathrm{D}}$. Therefore, for this class of cost functions and $a \geqslant 2$, irrespective of the distribution 
of preferences, price is higher under dual ownership even though quality is lower in that regime.

Theorem 4. When the (fixed) costs of quality provision of each of the components take the form $\phi(q)=c q^{a} / 2$ with $a \geqslant 2$, equilibrium price is higher under dual ownership than under sole ownership, even though equilibrium quality is lower under dual ownership.

The quality, price, surplus, and profits differences across ownership structures are very significant. For example, if the distribution is uniform on $[0,1]$, it is easy to show that $\theta_{\mathrm{S}}^{*}=1 / 2, \theta_{\mathrm{D}}^{*}=2 / 3$, so that $q_{\mathrm{s}}=\left(\frac{1}{4}\right)^{\frac{1}{a}-1} . v, q_{\mathrm{d}}=\left(\frac{2}{9}\right)^{\frac{1}{a}-1} . v, p_{\mathrm{S}}=$ $2^{-(a+1) /(a-1)} v, p_{\mathrm{D}}=\left(2^{a} 3^{-(a+1)}\right)^{\frac{1}{a}-1} v$, where $v=(a c)^{-1 /(a-1)}$. Then, at $a=2, q_{\mathrm{D}} /$ $q_{\mathrm{S}}=8 / 9$, and, $p_{\mathrm{S}} / p_{\mathrm{D}}=27 / 32$. Thus, in this example, vertical disintegration implies a quality deterioration of $11 \%$, a price increase of $16 \%$, and a reduction in market coverage by $33 \%$ (from $1 / 2$ to $1 / 3$ ). These differences imply that vertical disintegration results in a $60.5 \%$ reduction in consumers' surplus since $C S_{\mathrm{D}} /$ $C D_{\mathrm{S}}=32 / 81 \simeq 0.395$, a $21 \%$ reduction in profits since $\left(\Pi_{\mathrm{A}}^{*}+\Pi_{\mathrm{B}}^{*}\right) / \Pi_{\mathrm{S}}^{*}=64 /$ $81 \simeq 0.79$, and a $41 \%$ reduction in total surplus since $T S_{\mathrm{D}} / T S_{\mathrm{S}}=16 / 27 \simeq 0.59 .^{17}$

\section{Extensions}

All results can easily be extended to $n>2$ complementary products combined in fixed proportions. The calculations for the integrated monopolist do not change except for the extra fixed costs for each of the $n$ components. Price equilibrium for disintegrated monopolists is similar, with $n$ substituted for 2 in Eq. (8):

$$
\partial \Pi_{\mathrm{A}} / \partial p_{\mathrm{A}}=\partial \Pi_{\mathrm{B}} / \partial p_{\mathrm{B}}=1-F\left(\theta^{*}\right)-\theta^{*} f\left(\theta^{*}\right) / n=0 .
$$

Then the argument proving $\theta_{\mathrm{S}}^{*}<\theta_{\mathrm{D}}^{*}$ and $p_{\mathrm{S}}(q)<p_{\mathrm{D}}(q)$ follows as before. The argument of Theorem 2, proving that quality is lower in disintegrated ownership, again can easily be replicated for $n$ complementary goods. Similarly, the welfare comparisons of Theorem 3 follow directly. Finally, the argument for Theorem 4 also follows in the same manner as for two firms; thus price is also higher for disintegrated monopolists with power functions as fixed costs of quality.

The results can also be extended to other specifications of the composite good's quality as a function of the qualities of the components. The minimum function, $\min \left(q_{1}, q_{2}\right)$, is the limit of a constant elasticity of substitution function as the

\footnotetext{
${ }^{16}$ Note that $a \geqslant 2$ is a sufficient condition. For some distribution functions, $p_{\mathrm{S}}<p_{\mathrm{D}}$ holds for smaller $a, 1<a<2$.

${ }^{17}$ See also Economides and Lehr (1995).
} 
elasticity of substitution tends to zero. In general, we may posit that the quality of the composite good is $q_{\mathrm{AB}}=\left[\left(q_{\mathrm{A}}^{\rho}+q_{\mathrm{B}}^{\rho}\right) / 2\right]^{1 / \rho}$, which implies a constant elasticity of substitution $\sigma=1 /(1-\rho)$. It is easy to show that the limit as $\sigma \rightarrow 0$ (equivalently as $\rho \rightarrow-\infty$ ) of this CES function is the minimum function. By continuity, all results established for the minimum function hold for the CES function with small elasticity of substitution $\sigma$.

\section{Concluding remarks}

We have discussed the effect of vertical integration of two monopolists on the quality level of composite goods. The effects of the lack of vertical integration on price are known. The interesting result established here is that lack of vertical integration leads to a reduction in quality, lower market coverage, and smaller consumer surplus and profits. These results do not arise from a lack of coordination between the disintegrated (dual) monopolists in the choice of quality, since they both choose the same quality level. Instead, the difference of quality between the two ownership structures arises out of the change of the strategic incentives implied by the different ownership structures. In disintegrated ownership, quality improvements have a bigger impact on price; thus, firms save on quality costs by choosing a lower quality while achieving the same impact on price.

We also proved for a wide class of cost functions and any distribution of consumers that, despite the provision of a lower quality level, disintegrated monopolists will charge a higher price, in comparison with a vertically integrated monopolist. Finally, the results of this paper were established in a framework of no economies of scope and no costs of coordination. Introduction of either economies of scope or costs of coordination would strengthen our results.

An interesting question for further research is the extent that these results can be generalized in other market structures, where there is a degree of competition in the market for each component. In the presence of competition, the issue of quality choice is more complicated since vertically integrated firms have the option to produce components that are totally or partially incompatible with products (or components) of competitors, thereby foreclosing or disadvantaging competitors. Under these circumstances, a vertically integrated firm with significant market power in the market for at least one of the components may also have incentives to raise the costs of rivals in one or both markets by either degrading quality or creating incompatibilities. ${ }^{18}$ Thus, in the presence of competition, strategic decisions of quality provision should be analyzed in conjunction with decisions on the degree and extent of compatibility. ${ }^{19}$

\footnotetext{
${ }^{18}$ See Economides (1997).

${ }^{19}$ For a comprehensive discussion of compatibility and related issues, see Economides (1996).
} 


\section{Acknowledgements}

I thank Bill Greene, Charlie Himmelberg, Barbara Katz, Bill Lehr, Steve Levinson, Pino Lopomo, Rob Masson, Chris Stefanadis, Larry White, and an anonymous referee for helpful comments and suggestions.

\section{References}

Cournot, A., 1927. Researches into the Mathematical Principles of the Theory of Wealth (Bacon, N.T. Trans.). Macmillan, New York (original work published in 1838).

Economides, N., 1996. The economics of networks. International Journal of Industrial Organization 14 (2), 675-699.

Economides, N., 1997. The incentive for non-price discrimination by an input monopolist. Discussion paper No. 486, Center for Economic Policy Research, Stanford University.

Economides, N., Lehr, W., 1995. The quality of complex systems and industry structure. In: Lehr, W. (Ed.), Quality and Reliability of Telecommunications Infrastructure. Lawrence Erlbaum, Hillsdale.

Economides, N., Salop, S.C., 1992. Competition and integration among complements, and network market structure. Journal of Industrial Economics 40 (1), 105-123.

Sonnenschein, H., 1968. The dual of duopoly is complementary monopoly: Or, two of Cournot's theories are one. Journal of Political Economy 36, 316-318. 